
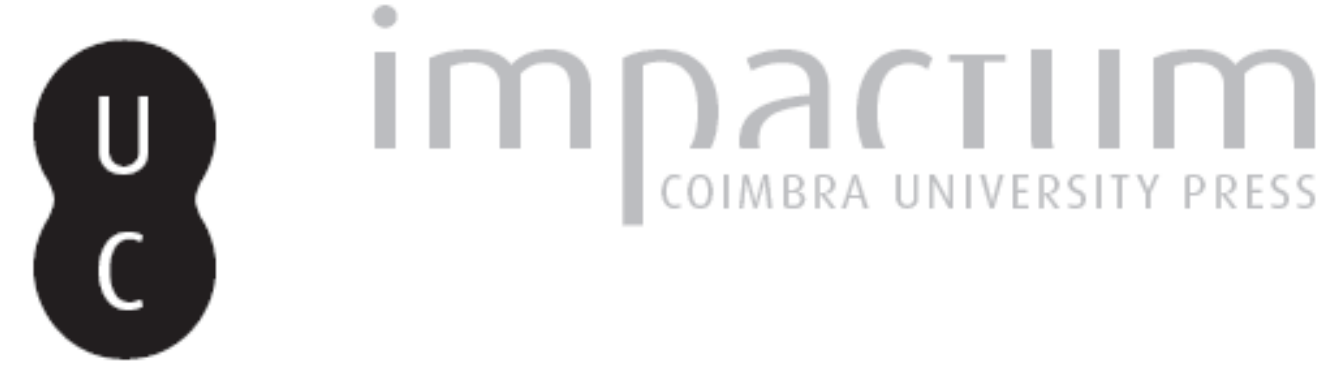

\title{
[Recensão a] Maria Luiza Tucci Carneiro, Preconceito racial no Brasil Colónia. Os Cristãos Novos. Com um Prefácio de Anita Novinsky
}

Autor(es): $\quad$ Torgal, Luís Reis

Publicado por: Imprensa da Universidade de Coimbra

URL persistente:

URI:http://hdl.handle.net/10316.2/45294

DOI:

DOI:https://doi.org/10.14195/2183-8925_8-1_34

Accessed : $\quad$ 26-Apr-2023 13:14:27

A navegação consulta e descarregamento dos títulos inseridos nas Bibliotecas Digitais UC Digitalis, UC Pombalina e UC Impactum, pressupõem a aceitação plena e sem reservas dos Termos e Condições de Uso destas Bibliotecas Digitais, disponíveis em https://digitalis.uc.pt/pt-pt/termos.

Conforme exposto nos referidos Termos e Condições de Uso, o descarregamento de títulos de acesso restrito requer uma licença válida de autorização devendo o utilizador aceder ao(s) documento(s) a partir de um endereço de IP da instituição detentora da supramencionada licença.

Ao utilizador é apenas permitido o descarregamento para uso pessoal, pelo que o emprego do(s) título(s) descarregado(s) para outro fim, designadamente comercial, carece de autorização do respetivo autor ou editor da obra.

Na medida em que todas as obras da UC Digitalis se encontram protegidas pelo Código do Direito de Autor e Direitos Conexos e demais legislação aplicável, toda a cópia, parcial ou total, deste documento, nos casos em que é legalmente admitida, deverá conter ou fazer-se acompanhar por este aviso.

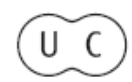


REVISTA DE HISTÓRIA DAS IDEIAS $\mathbf{8}$

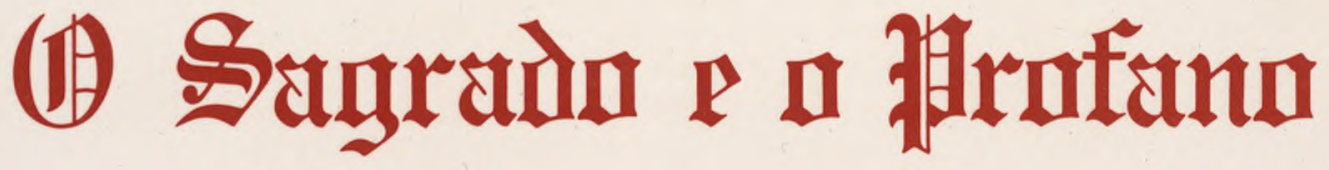 s.1. \\ HOMENAGEM A J. S. DA SILVA DIAS}

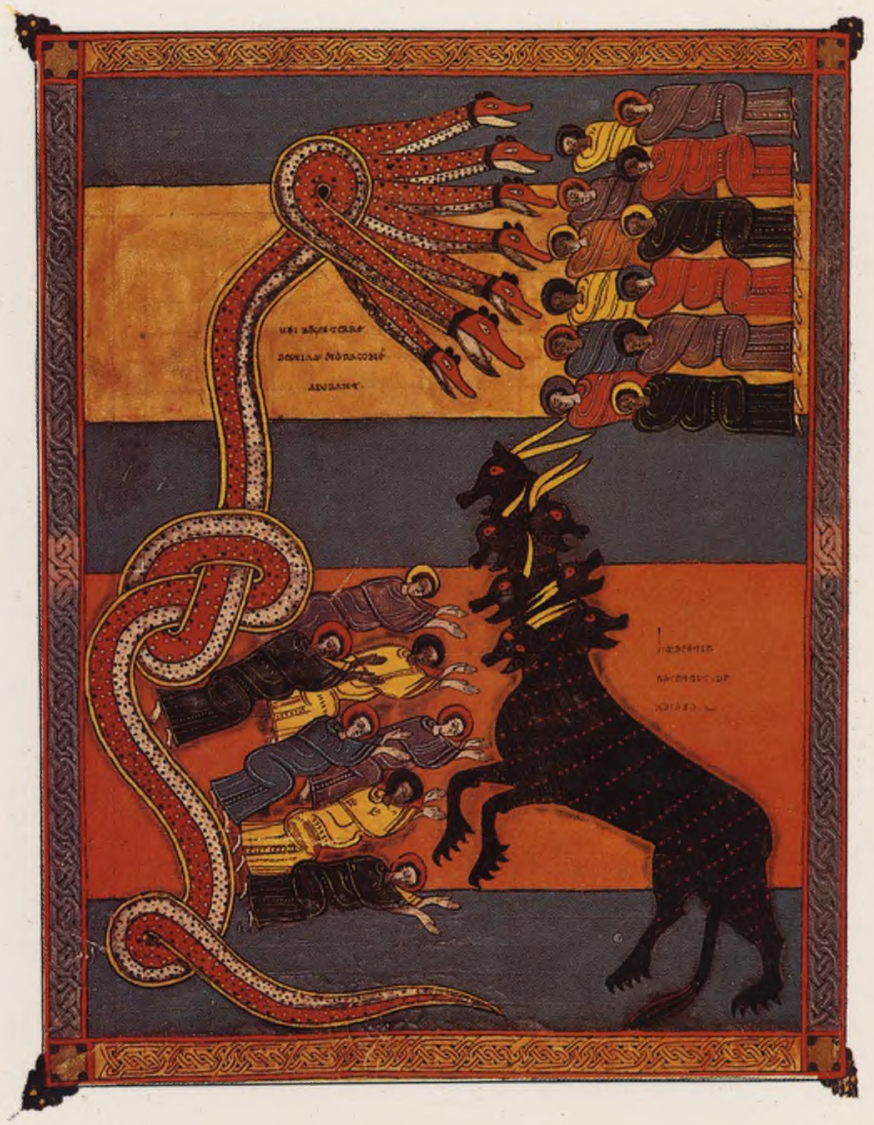

INSTITUTO DE HISTORIA E TEORIA DAS IDEIAS FACULDADE DE LETRAS 
Maria Luiza Tucci Carneiro, Preconceito racial no Brasil Colónia. Os Cristãos Novos. Com um Prefácio de Anita Novinsky, São Paulo, Editora Brasiliense, 1983, 727 pp.

O escasso conhecimento que se verifica em Portugal da historiografia brasileira é, geralmente, uma realidade - uma realidade dramática, até porque pode ser entendida como um dos sinais reveladores da falta de uma sólida consciência cultural de expressão portuguesa. A mesma situação é demonstrada, por sua vez, pela generalizada carência de informação que no Brasil se manifesta em relação à nossa historiografia. Importamos, com maior ou menor critério e proveito, a produção historiográfica de outros países, nomeadamente de França, mas com alguma dificuldade encontramos nas nossas bibliotecas e livrarias obras dos investigadores do lado de lá do Atlântico que falam a nossa língua, tiveram um passado histórico em grande parte comum e abordam temas que nos são familiares. De modo paralelo, as livrarias do Rio e de Brasília - e por certo de São Paulo, da Baía e de outras cidades que não conheço - primam pela ausência de obras portuguesas, enquanto na Biblioteca Nacional do Rio de Janeiro se depara, conforme eu próprio pude observar, com confrangedoras lacunas relativamente às nossas publicações.

Vem tudo isto - em fase de superação? - a propósito de uma série de obras que me chegaram às mãos de historiadores brasileiros, uns iniciantes na prática de pesquisa histórica, outros já com nome firmado. Na realidade, quero confessar que desconhecia o nome de alguns e sobretudo não ouvira falar nem sequer dos títulos de certos livros. E poderei afirmar agora que, lamentavelmente, não conhecia textos fundamentais ou, pelo menos, curiosas obras de divulgação e experiências de investigação do maior interesse.

A obra da jovem historiadora Maria Luiza Tucci Carneiro Preconceito racial no Brasil Colónia situa-se entre essas experiências. Orientada pela professora Anita Novinsky - uma especialista em história da Inquisição e dos cristãos-novos - trata-se de uma dissertação de Mestrado indiciadora das excelentes potencialidades da sua autora. De resto, vem apenas confirmar o crédito que já há muito tem entre nós a escola de historiadores da Universidade de São Paulo.

Distribuída por 4 capítulos, para além de uma Introdução e uma Conclusão, a obra trata dos seguintes temas gerais, depois divididos em vários subtemas: «Historiografia e racismo» (cap. I), «O Preconceito Racial contra os Cristãos-Novos em Portugal» (cap. II), «Pombal e a Eliminação Legal do Precon- 
ceito de Sangue» (cap. Ill) e «Transferência Racial contra os Cristãos-Novos para o Brasil Colónia» (cap. IV).

No primeiro capítulo Maria Luiza procurou fazer um levantamento crítico da historiografia e da sociologia brasileira e estrangeira relativas à problemática do racismo. Tratava-se, efectivamente, de uma tarefa prioritária, para evitar «prejuízos» e distinguir interpretações ideológicas, sem o que a análise histórica não consegue alcançar a objectividade possível. Com isto, todavia, não pretendo afirmar que a história possa ser «neutra» e que o verdadeiro historiador tem de fazer parte daquela intelligentsia concebida por Mannheim, daquele grupo sem laços sociais e sem ideologias com uma autêntica vocação científica.

O problema do racismo preocupa todos os países do mundo, mas sobretudo aqueles que resultam de processos coloniais (como é o caso do Brasil), nunca de resto abolidos, como sobrevivência ou como trauma. Aliás o racismo, para além de uma situação institucional, é sobretudo uma situação cultural e mental, caracterizada pela desvalorização ou não compreensão das culturas regionais ligadas a raças ou etnias. É, pois, uma questão fundamental a ser estudada, numa perspectiva sociológica ou histórica, sem preconceitos ideológicos, sem processos científicos sistémicos, mas também partindo do princípio de que a ciência supõe necessariamente, embora não como um grilhão mas como uma direcção de análise, concepções teóricas mais ou menos ligadas a ideologias. Por isso, se se justifica a reflexão crítica por parte da autora do «mito da democracia racial» brasileira de Gilberto Freire, também se justificaria uma análise sobre o enquadramento ideológico do escritor da Casa Grande e Senzala. Tal como em relação aos outros autores que foi referindo. Será que se pode realmente afirmar que Caio Prado Junior «superou as formas de pensamento ideológico que marcaram os primeiros séculos dos estudos históricos, antropológicos e sociológicos no Brasil»? A questão não é essa, segundo penso: ele terá iniciado um outro processo científico que supôs necessariamente outras teorias ligadas a outras concepções ideológicas.

O capítulo II apresenta uma análise de «longa duração» em que procura detectar as «origens do estatuto, da pureza de sangue» e o seu processo de institucionalização. É uma interessante tentativa de levantamento dos sinais mais reveladores, captados sobretudo através do estudo da legislação. Evidentemente que algumas questões ficaram por conhecer com profundidade, mas tal facto justifica-se não só pela falta de tempo - é uma tese de Mestrado a obra que estamos a analisar, recorde-se _-, mas até pelo tipo de análise estrutural realizada, que supõe, quase sempre, uma subalternização da realidade conjun- 
tural, todavia importante para melhor delinear toda a complexidade da historia. Por sua vez, o problema do «preconceito racial contra os cristãos-novos em Portugal» só pode ser devidamente compreendido através da leitura de alguns processos inquisitoriais exemplares, que Maria Luiza não pôde contactar. Também o recurso a algumas obras importantes, a que parece não ter tido acesso, lhe teria por certo possibilitado outro tipo de reflexão. Referimo-nos, por exemplo, a alguns capítulos da obra de Silva Dias A política cultural da época de D. João III e aos recentes estudos sobre os judeus de Maria José Pimenta Ferro.

Quanto ao capítulo III — «Pombal e a eliminação legal do preconceito de sangue» - consiste numa análise das medidas levadas a efeito pelo ministro de D. José contra o "puritanismo» (cuidado com a palavra, que tem na língua portuguesa um sentido geralmente diferente - significa aqui, de acordo com a acepção que na documentação do tempo tinha, o movimento aristocrático que defendia a «pureza de sangue»). A posição de Pombal contra o «puritanismo» - conforme o procura revelar a autora - é bem demonstrativa da acção do «absolutismo esclarecido» contra uma certa concepção de nobreza, entendida como ordem desligada dos «interesses do Estado» e assim como uma espécie de contra-poder. Parece-me correcta esta interpretação, mas julgo também que ela pode originar uma simplificação explicativa quanto ao sentido sociológico do movimento antijudaico se o problema não for profundamente analisado. Concretamente: pode levar à interpretação, que a autora parece reflectir, de que o estatuto da «pureza de sangue» é assumido em exclusivo, ou pelo menos dominantemente, pela «ordem nobiliárquica-eclesiástica». Se, evidentemente, poderia ser essa a opinião do Pombalismo, que interpretava a atitude em termos de «razão de Estado», não parece que ela possa ser exactamente assim considerada através de uma análise da realidade histórica. Pelo menos precisa de ser por ela confirmada. Julgo, com efeito, que o problema é mais complexo. Direi brevemente, apenas com n objectivo de levantar questões, que o «racismo» em relação aos cristãos-novos havia sido defendido não só por um sector eclesiástico lusitano, representado por áreas influentes da Inquisição e por certas ordens religiosas que a apoiavam, como também - por interesse próprio e por efeito de uma reprodução ideológica - pelo sector burguês comerciante «cristão-velho» e até pelos sectores «mais populares» da sociedade portuguesa. De resto, não há documento mais revelador deste processo do que os capítulos do Terceiro Estado das Cortes de 1641 - eles constituem, de todos os capítulos das três ordens, os mais antijudaicos. Ao invés, os menos antijudaicos serão os da ordem 


\section{Recensões}

nobre, cada vez mais interessada nos «casamentos mistos». E recorde-se o papel dos jesuítas no século XVII — o Padre António Vieira não parece ser um caso isolado - a favor dos cristãos-novos e da revisão dos processos de actuação do Santo Ofício português. Parece-me, pois, que a defesa do «puritanismo» não se pode caracterizar como um simples processo «nobiliárquico-eclesiástico». Será talvez, isso sim, uma posição assumida por uma grande nobreza senhorial ligada a um clero ultramontano (em que na verdade os jesuítas portugueses se terão tornado, de resto em consonância com a sua posição nos países de tradição galicana), com os pequenos e médios comerciantes receosos da concorrência dos grandes traficantes de origem judaica e até com o «povo miúdo», traumatizado pela presença dos arrematadores de impostos geralmente de origem semita e influenciado pela força da ideologia antijudaica. Essa realidade social é diferente da realidade ideológica que o absolutismo pombalino se encarregou de divulgar a fim de justificar a sua actuação.

O capítulo IV aborda finalmente as questões centrais que correspondem ao título da obra. Penso que foi pena o facto de a autora não abordar com maior desenvolvimento tal temática, que se estende apenas por pouco mais de 50 páginas, o que confere ao livro (com cerca de 250 páginas de texto) um certo desequilíbrio. De qualquer forma, é muito importante a análise realizada, inclusivamente por algumas sugestões que fornece. É o caso do estudo linguístico dos vocábulos relativos aos cristãos-novos. Claro que a investigação feita nesse âmbito é ainda muito limitada e, dentre as palavras-chave do antijudaísmo, parecem-me faltar algumas fundamentais, como por exemplo «marrano». No entanto, permanece como muito interessante a abertura de um campo de estudo, que se pode revelar muito fecundo se for analisado num espaço de interdisciplinaridade, em que a História, a Linguística e a Antropologia Cultural dêem as mãos.

As críticas que fiz só até certo ponto terão sentido e, se as produzi, foi porque o livro de Maria Luiza Tucci Carneiro me mereceu uma grande simpatia. Trata-se de um trabalho académico, de uma dissertação de Mestrado — recordo mais uma vez - e por isso deve ser encarado como tal. E nessa perspectiva ele indica caminhos fundamentais a seguir, como revela desde já as qualidades de investigação da sua autora. Hoje, à frente da área de História Ibérica da Universidade de São Paulo, Maria Luiza atingiu outra maturidade como historiadora. Mas esta sua obra será sempre um marco importante, como etapa a caminho de novos métodos e novas zonas de 
análise e ainda como sugestão para novos trabalhos que nós, portugueses, teremos também de realizar em colaboração com os «pesquisadores» brasileiros.

\section{Luís Reis Torgal}

Leopoldo Jobim, Ideologia e Colonialismo. Prefácio de Luís Viana Filho, Rio de Janeiro, Forense-Universitária, 1985, 131 pp.

1. Polarizado em torno da personalidade, dos escritos e da acção de Luís dos Santos Vilhena (1744-1814), Leopoldo Jobim, professor da Universidade de Brasília, acaba de publicar um importante trabalho sobre o pensamento político e económico do Brasil setecentista.

Com Ideologia e Colonialismo pretende o autor propor um espaço de reflexão mais adequado do' que foram as Luzes em Portugal. Chama a atenção para a sua tese, do que, em Chaunu, em La civilisation de VEurope des Lumières, foi o conceito de alargamento e absorção de áreas geográficas.

Neste aspecto, o que me parece questionável, logo de inicio, para enquadrar o autor, em volta de quem se faz interpretação sobre ilustração, no Brasil, é o tipo de atenção prestada a um posicionamento reformista para o qual, os Principes de la pensée au siècle des Lumières, de Gusdorf, não se tornarão, porventura os mais inspiradores. Devo confessar, que sempre fiquei de sobreaviso em relação a uma focalização predominantemente francesa e enciclopedista (ou de condicionamento francês). De facto, difícil se torna abordar temas e problemas de Luzes, em espaço e tempo português, desde os anos 60 até às últimas décadas de Setecentos sem, a par da influência das Luzes francesas, muitas delas reprimidas, não atender a uma ilustração italiana, à «Frueaufklárung», de expressão germânica, ou à Ilustração inglesa, ilustrações mais aceites pelo que tinham de simpatia para o projecto pombalino. E, também, na mesma linha de reparo, faria notar que a referência ao Newton, de Philosophie Naturalis Principia Mathematica, a que se poderia acrescentar, pela importância que teve para uma nova matriz epistemológica, a leitura do livro IV da Óptica, não pode ser dissociada da compleição de um neutonianismo moral, que fará curso entre nós, e que contribuiu ideologicamente para a mentalidade e sensibilidade que apelava para compromissos em que a inovação não perturbasse, no fundo, um entendimento de valores que se querem reportados tanto às coisas da natureza, - ou seja pelo paradigma da «autonomia das ciências 